\title{
PELATIHAN SPIRITUAL EMOTIONAL FREEDOM TECHNIQUE (SEFT) UNTUK MENINGKATKAN KUALITAS TIDUR DAN STABILITAS TEKANAN DARAH PASIEN HIPERTENSI
}

\section{SPIRITUAL EMOTIONAL FREEDOM TECHNIQUE (SEFT) TRAINING TO IMPROVE SLEEP QUALITY AND BLOOD PRESSURE STABILITY OF HYPERTENSIVE PATIENTS}

\author{
Beti Kristinawati $^{1}$, Siti Rahmawati ${ }^{2}$, Aisyah Nur Fadhila ${ }^{3}$, Rizki Amin Nur Fadhila ${ }^{4}$ \\ ${ }^{1}$ Department of Medical-Surgical Nursing, School of Nursing, Universitas Muhammadiyah Surakarta, \\ Surakarta, Indonesia. \\ 2 Professional Nursing Student, School of Nursing, Universitas Muhammadiyah Surakarta, Solo, Indonesia. \\ ${ }^{3,4}$ Bachelor Degree Nursing Student, School of Nursing, Universitas Muhammadiyah Surakarta, Solo, \\ Indonesia \\ *Corresponding author: bk115@ums.ac.id
}

\begin{abstract}
ABSTRAK
Kata Kunci:

Hipertensi,

Kualitas Tidur,

SEFT dan

Tekanan Darah

Tekanan darah yang tidak stabil pada penderita hipertensi dapat diakibatkan oleh kebutuhan istirahat tidur tidak terpenuhi. Kualitas tidur yang kurang disertai tekanan darah tinggi yang tidak tertangani dengan baik akan berdampak pada munculnya komplikasi dan resiko terburuk terjadi kematian. Upaya mengendalikan hipertensi dapat dilakukan dengan terapi komplementer Spiritual Emotional Freedom Technique (SEFT). Tujuan dilakukannya pengabdian masyarakat ini adalah meningkatkan pengetahuan dan kemampuan penderita hipertensi dalam melakukan terapi komplementer SEFT untuk meningkatkan kualitas tidur dan menjaga stabilitas tekanan darah. Pelatihan SEFT dilakukan empat sesi latihan, mulai tanggal 22-25 Februari 2021. Jumlah total peserta pelatihan 44 lansia, dengan peserta tiap sesi dibatasi 11 orang. Peningkatan pengetahuan dan kemampuan melakukan SEFT secara mandiri diukur dengan pre dan post tes. Kegiatan pelatihan dilakukan dengan tetap menjalankan protokol kesehatan untuk mencegah penyebaran Covid 19. Kegiatan pelatihan yang menjadi bagian dari pengabdian pada masyarakat dilakukan di Desa Ngrambe, Kabupaten Ngawi. Hasil menunjukkan bahwa setelah diberikan pelatihan, pengetahuan peserta pelatihan tentang manfaat terapi koplementer SEFT meningkat antara sebelum dan sesudah sesi Latihan. Hasil pre test menunjukkan dari 7 pertanyaan yang diajukan, hanya 2-3 soal yang mampu dijawab. Sedangkan hasil post test meningkat menjadi 5-7 mampu dijawab. Disimpulkan bahwa pelatihan yang telah dilakukan dapat meningkatkan pengetahuan tentang terapi komplementer SEFT dan diharapkan mampu menjadi terapi tambahan untuk meningkatkan kualitas hidup penderita hipertensi.
\end{abstract}

\section{ABSTRACT}

Keywords:

Hypertension,

Sleep Quality,
Unstable blood pressure in people with hypertension can result from unmet sleep rest needs. Poor sleep quality accompanied by high blood pressure that is not appropriately handled will impact the emergence of complications and the worst risk of death. Efforts to control hypertension can be made with complementary spiritual, emotional freedom 
SEFT and Blood

Pressure techniques (SEFT). The purpose of this community service is to increase the knowledge and ability of people with hypertension in performing SEFT complementary therapies to improve sleep quality and maintain blood pressure stability. SEFT training is conducted in four training sessions, from February 22-25, 2021. The total number of trainees is 44 elderly, with each session limited to 11. Increased knowledge and ability to perform SEFT independently are measured by pre and post-tests. Training activities are carried out while maintaining health protocols to prevent the spread of Covid 19. Training activities that are part of the community are carried out in Ngrambe Village, Ngawi Regency. Results showed that after being given the training, trainees' knowledge of the benefits of SEFT complementary therapy increased between before and after the exercise session. Pre-test results showed that of the seven questions asked, only 2-3 questions were answered. While the post-test results increased to 57 can be answered. It was concluded that the training done could increase knowledge about SEFT as complementary therapies and is expected to be an additional therapy to improve the quality of life of people with hypertension.

Keywords: Hypertension, Sleep Quality, SEFT and Blood Pressure.

\section{PENDAHULUAN}

Hipertensi atau tekanan darah tinggi (high blood pressure) adalah kondisi dimana darah yang mengalir melalui arteri mengalami tekanan yang lebih tinggi dari keadaan normal-120/80 $\mathrm{mmHg}$ pada orang dewasa (National Heart Lung and Blood Institute / NHLBI, 2020). Peningkatan jumlah penderita hipertensi yang mengalami gangguan tidur dan status tekanan darah yang tidak stabil menjadi permasalahan kesehatan serius. World Health Organization (WHO) menyebutkan bahwa penderita hipertensi mencapai angka 1,13 miliar orang di seluruh dunia dengan dua pertiganya tinggal di negara berpenghasilan rendah dan menengah. Kasus hipertensi yang terus meningkat juga terjadi di Indonesia (93 World Health Organization (WHO) Unknown - Hypertension1, n.d.). Hasil Riset Kesehatan Dasar (Riskesdas) tahun 2018 terjadi peningkatan angka kejadian hipertensi di Indonesia dengan jumlah penduduk sekitar 267,7 juta (Riskesdas, 2018). Data dari Dinas Kesehatan Provinsi Jawa Tengah tahun 2016 menyatakan kasus tertinggi penyakit tidak menular (PTM) adalah kelompok penyakit hipertensi yang menempati jumlah terbesar dari seluruh PTM yang dilaporkan, yaitu sebesar $60 \%$ (Riset Kesehatan Dasar Provinsi Jawa Tengah, 2018).
Peningkatan prevalensi hipertensi di dunia maupun di Indonesia terjadi karena beberapa faktor. Hasil penelitian yang dilakukan oleh (Martini et al., 2018) Martini et al., (2018) menyebutkan pengaruh yang paling tinggi terhadap kejadian hipertensi adalah pola tidur. Pola tidur termasuk salah satu faktor penyebab hipertensi dengan faktor risiko yang dapat dimodifikasi. Ketika seseorang tidak dapat memodifikasi pola tidur dengan efektif maka akan menjadi kebiasaan selama terdiagnosa hipertensi dan mempunyai kualitas tidur buruk. Kualitas tidur berkaitan erat dengan status tekanan darah, dimana jika mengalami durasi tidur pendek dalam jangka lama akan meningkatkan aktivitas saraf simpatik sehingga timbul stress dan berakibat naiknya tekanan darah. Hubungan kualitas tidur dan status tekanan darah yang tidak terkendali akan menyebabkan masalah lain penderita hipertensi (Alfi \& Yuliwar, 2018).

Upaya dalam mengendalikan masalah penderita hipertensi dapat dilakukan yaitu dengan terapi farmakologi dan non farmakologi. Terapi farmakologi dilakukan dengan pemberian jenis-jenis obat medikasi antihipertensi sesuai pedoman (Cuspidi et al., 2018). Namun, obat-obat yang dikenal sebagai first line drug apabila dikonsumsi dalam jangka lama dapat menyebabkan terjadinya (DRPs) atau Drug Related Problems (Ainurrafiq et al., 2019). Penggunaan pengobatan penderita hipertensi dengan terapi non farmakologi bisa dilakukan 
diantaranya terapi pengaturan tidur, terapi psikologi dan terapi relaksasi (Yani et al., 2019). Terapi tersebut bekerja merelaksasikan tubuh, menurunkan tekanan darah dan merangsang sirkulasi peredaran darah dan menjadikan resistensi vascular perifer menurun (Alparslan et al., 2016). Ada beberapa terapi yang termasuk ke dalam teknik relaksasi, salah satunya adalah terapi Spiritual Emotional Freedom Technique (SEFT).

SEFT merupakan salah satu bentuk mindbody therapy dari terapi komplementer keperawatan sebagai alternatif pengobatan hipertensi (Hidayatulloh \& Lismayanti, 2018). Penelitian yang dilakukan oleh Murni (2018) mengungkapkan bahwa terapi SEFT menggabungkan terapi spiritual dan sistem tubuh (energy medicine) dengan metode tapping. Metode ini bekerja merangsang beberapa titik kunci pada sepanjang 12 jalur energi tubuh (energy meridian). Hasil penelitian yang dilakukan oleh Kasron \& Susilawati, (2017) tentang pengaruh Spiritual Emotional Freedom Technique (SEFT) terhadap kualitas tidur penderita hipertensi di Cilacap Selatan menunjukkan sebagian besar responden mengalami peningkatan kualitas tidur yang lebih baik (Kasron \& Susilawati, 2017). Terapi SEFT digunakan untuk menenangkan hati yang diharapkan meningkatkan unsur spiritual dan melepaskan pikiran yang sesak dari unsur emosional (Cholifah et al., 2020). Terapi ini memberikan rasa tenang karena terjadi proses keseimbangan antara energi tubuh sehingga menimbulkan efek relaksasi dan tekanan darah menjadi stabil. Kondisi ini didukung oleh hasil penelitian Huda \& Alvita, (2018) tentang pengaruh terapi SEFT (Spiritual Emotional Freedom Technique) terhadap penurunan tekanan darah pada penderita hipertensi menunjukkan pengaruh terapi SEFT yang signifikan terhadap penurunan tekanan darah pada penderita hipertensi (Huda \& Alvita, 2018). Perilaku perawatan hipertensi secara adekuat dapat mencegah dan mengurangi kekambuhan hipertensi sehingga kualitas tidur meningkat (Setyaningrum, 2019).
Hasil studi pendahuluan menyatakan data kunjungan secara global yang diperoleh dari UPTD Puskesmas Ngrambe Kabupaten Ngawi terdapat 2.696 pasien hipertensi. Angka tersebut terhitung dari bulan Januari 2020 sampai bulan Agustus 2020 dengan rata-rata pasien perbulan berjumlah 337 orang yang telah mencakup pasien prolanis. Pada Program Pengelolaan Penyakit Kronis atau Prolanis UPTD Puskesmas Ngrambe terdapat 45 pasien hipertensi. Prolanis UPTD Puskesmas Ngrambe berlangsung dengan kegiatan pemberian obat yaitu saat jadwal pasien kontrol sebanyak tiga kali per bulan dengan jumlah 15-20 orang setiap pertemuan atau sesuai waktu luang pasien di jam kerja puskesmas.

Wawancara dilakukan dengan 8 orang pasien hipertensi yang menjalani rawat jalan Prolanis dan tenaga kesehatan penanggung jawab pemeriksaan lansia di Puskesmas Ngrambe mengatakan bahwal lansia yang mengikuti kegiatan Prolanis hanya menggunakan terapi farmakologi dengan rutin minum obat, dan belum menggunakan terapi komplementer sebagai terapi tambahan dalam menjaga tekanan darah agar tetap stabil. Namun pasien masih mengeluhkan tekanan darah yang naik turun dan mengalami gangguan tidur walaupun sudah rutin meminum obat. Gangguan tidur yang dialami seperti memikirkan masalah, tidur larut malam karena menonton televisi, merasa badan tidak enak (pegal, kaku, nyeri dll), bangun di tengah malam karena BAK bahkan tiba-tiba bangun tengah malam tanpa alasan. Pemberian terapi non farmakologi berperan dalam pengaturan fisik dan psikologis pasien hipertensi yang mengalami gangguan tidur.

Tujuan dari pengabdian masyarakat ini adalah meningkatkan pengetahuan masyarakat tentang pentingnya terapi non farmakologi SEFT untuk meningkatkan kualitas tidur dan Stabilitas Tekanan Darah Pasien Hipertensi.

\section{METODE}

Edukasi diberikan pada 44 anggota prolanis di wilayah Puskesmas Ngrambe, karena 
pengabdian masyarakat dilakukan saat pandemi covid 19 untuk proses pemberian pelatihan dilakukan dengan menggunakan protokol kesehatan dan meminimalkan kerumunan. Pelatihan SEFT dilakukan mulai tanggal 22-25 Februari 2021 dengan pembatasan jumlah responden untuk tiap sesi pelatihan adalah 11 lansia dan jeda pemberian pre test, Pelatihan SEFT, dan post test adalah 15 menit. Proses pengabdian masyarakat dilakukan dengan tetap menjalankan prosedur protokol kesehatan untuk mencegah penyebaran covid 19

Pelaksanaan secara umum dibagi menjadi 2 tahap yaitu:

1. Tahap pertama yaitu penyusunan materi latihan SEFT. Materi dibuat dan dirancang sedemikian rupa dan disesuaikan dengan kondisi masyarakat. Materi dibuat semenarik mungkin agar meningkatkan minat pembaca dari masyarakat. Pada materi latihan terdapat beberapa informasi seperti pengertian, tanda gejala, penatalaksaan non farmakologi yang dapat dilakukan dirumah.

2. Tahap Penyuluhan

a. Rapat anggota: bertujuan untuk mempersiapkan dan menyatukan persepsi anggota dengan ketua. Rapat ini membahas hal yang umum mengenai kesiapan program, langkah-langkah yang akan diambil, dan membagi tugas setiap anggota.

b. Rapat koordinasi: bertujuan untuk menyatukan persepsi antara tim pengabdian masyarakat dengan mitra.

c. Pembentukan educator

Pada program ini yaitu ibu Ns. Beti

Kristinawati, M. Kep., Sp.

Kep.M.B.

d. Mengidentifikasi kelompok sasaran

Pengidentifikasian kelompok sasaran ini berdasarkan ketersediaan sumber daya serta menggali seberapa jauh pengetahuan mengenai penyakit hipertensi dan terapi nya dengan memberikan pretest.

e. Pertemuan dengan kelompok sasaran

Penjelasan mengenai maksud serta tujuan. Dilanjutkan dengan penyampaian materi mengenai pelatihan SEFT untuk meningkatkan kualitas tidur dan stabilitas tekanan darah pasien hipertensi. Kegiatan di lanjutkan dengan diskusi, tanya jawab dari audien, dan praktek. Kegiatan pengabdian masyarakat diikuti oleh 44 orang, yang dijelaskan dalam tabel 3.1

f. Monitoring dan evaluasi

Setelah dilaksanakan pemberian pelatihan dilanjutkan dengan memonitoring hasil dan evalusai seberapa jauh penderita memahami informasi yang telah didapatkan dengan dierikan posttest dimana pertanyaan sudah disiapkan tentang informasi yang sebelumnya sudah diberikan.

Tabel 3. 1 Distribusi Frekuensi Karakteristik Demografi Responden

\begin{tabular}{lccc}
\hline \multicolumn{1}{c}{ Karakteristik } & $\mathrm{N}$ & $\%$ & Mean \pm SD \\
\hline Usia & & & \\
$\quad$ 45-54 tahun & 12 & 13,6 & $2,36 \pm 0,727$ \\
55-64 tahun & 12 & 36,4 & \\
$\quad$ 65-74 tahun & 20 & 50,0 & \\
\hline Agama & & & $1,09 \pm 0,294$ \\
$\quad$ Islam & 40 & 90,9 &
\end{tabular}




\begin{tabular}{llll} 
Katholik & 4 & 9,1 & \\
\hline Jenis Kelamin & 14 & 27,3 & \\
Laki-laki & 30 & 72,7 & \\
$\quad$ Perempuan & 9 & 18,2 & \\
\hline Pendidikan & 13 & 27,3 & $2,68 \pm 1,129$ \\
SD & 14 & 22,7 & \\
SMP & 8 & 31,8 & \\
SMA & & & \\
Sarjana & 14 & 36,4 & \\
\hline Pekerjaan & 9 & 27,3 & \\
Petani & 13 & 22,7 & \\
PNS & 3 & 0 & 1,352 \\
IRT & 5 & 13,6 & \\
Pedagang & & & \\
Karyawan & 25 & 50,0 & \\
\hline Lama Hipertensi & 17 & 50,0 & \\
1-5 tahun & 2 & 0 & $2,27 \pm 1,352$ \\
6-10 tahun & & & \\
16-20 tahun & 15 & 31,8 & \\
\hline Penyakit Penyerta & 19 & 40,9 & \\
Tidak ada & 3 & 9,1 & \\
Diabetes melitus & 3 & 4,5 & \\
Kolesterol & 4 & 13,6 & \\
Asam urat & & & \\
Jantung & & & \\
\hline & & & \\
\hline
\end{tabular}

Tabel 4.1 Hasil Pre Test dan Post Test Pelatihan SEFT

8

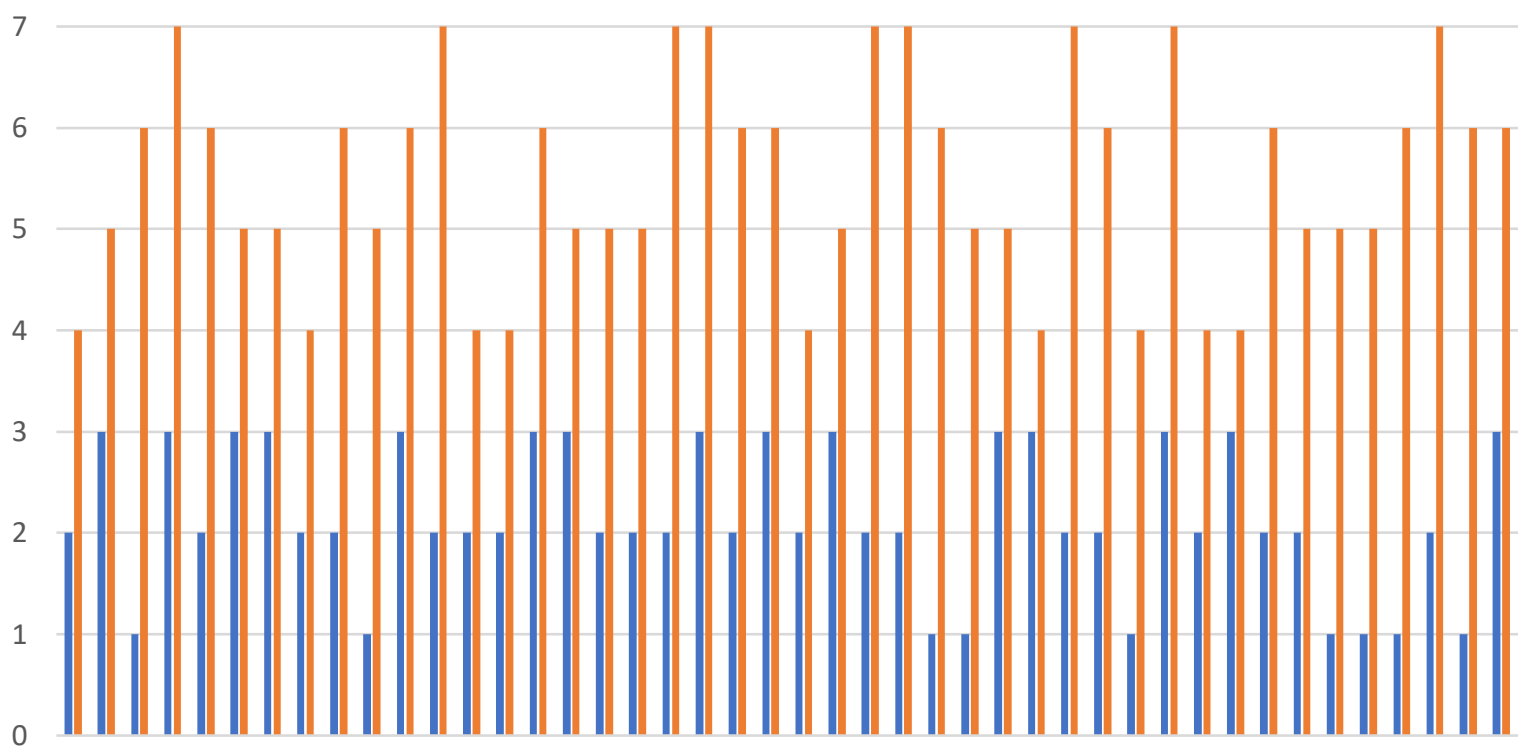

1234567891011121314151617181920212223242526272829303132333435363738394041424344

- Pre Test $\quad$ Post Test 


\section{Dokumentasi Kegiatan Pengabdian Masyaraakat Pelatihan SEFT}

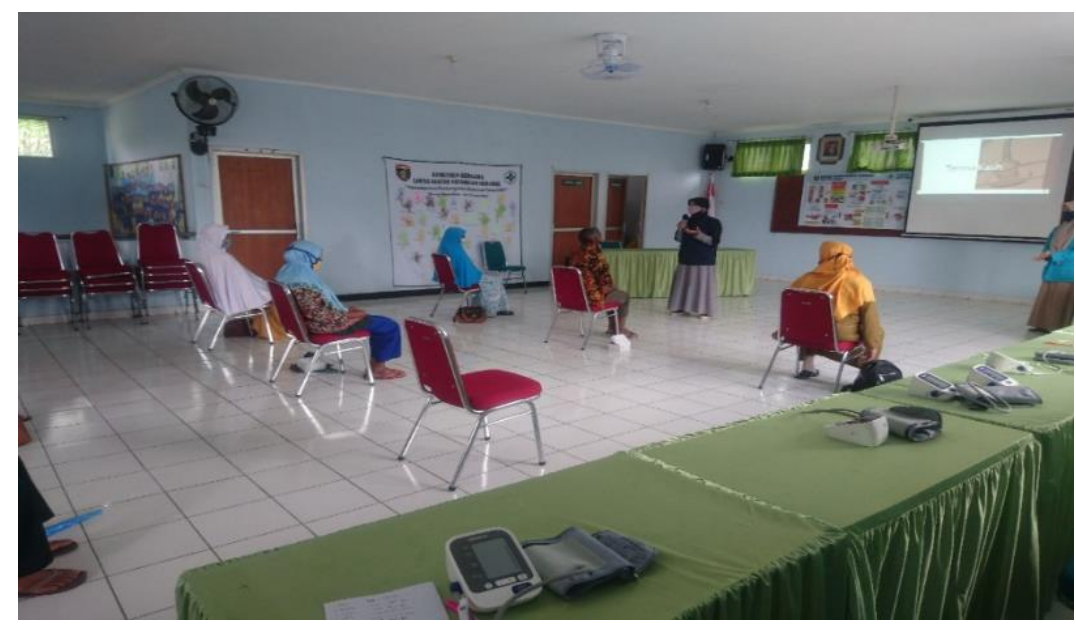

Gambar 1. Penjelasan Manfaat dan Teknik Melakukan SEFT oleh Pemateri

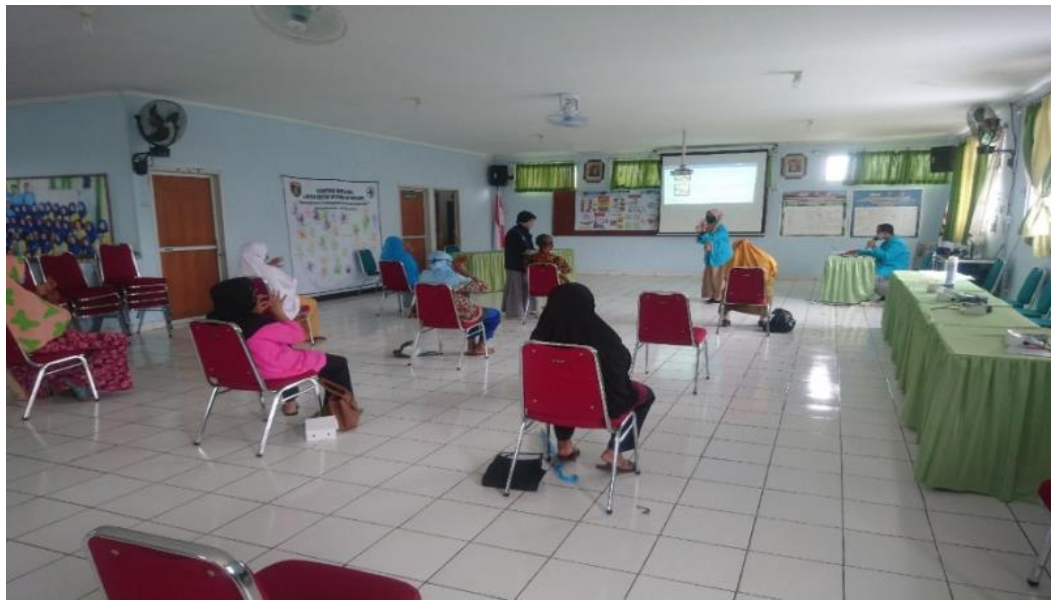

Gambar 2. Peserta Melakukan SEFT dengan Pendampingan

\section{HASIL DAN PEMBAHASAN}

Pengabdian masyarakat dilaksanakan pada Hari Senin-Kamis, 22-25 Februari 2021 pukul 09.00 WIB. Pelaksanaan kegiatan dilakukan di Aula Puskesmas Ngrambe, dengan diikuti 44 anggota Prolanis Puskesmas Ngrambe. Kegiatan pengabdian masyarakat dimulai dengan pre test, pemberian materi, dilanjutkan dengan diskusi dan praktik terapi kompelementer SEFT secara langsung yang dipandu oleh instruktur dan fasilitator, setelah itu dilakukan post test. Peserta tampak antusias dan semangat mempraktikan terapi SEFT bersama instruktur dan fasilitator. Kegiatan pengabdian kepada masyarakat yang telah dilakukan menunjukkan bahwa masyarakat dengan gangguan tidur dan tekanan darah yang tidak stabil mengalami peningkatan pengetahuan dan kemampuan mandiri dalam mempraktikkan terapi komplementer Spiritual Emotional Freedom Technique SEFT yang telah diajarkan. Hal tersebut ditunjukkan dengan kemampuan masyarakat menjawab pertanyaan dari instruktur dan mampu melakukan terapi komplementer SEFT secara mandiri saat pelatihan dilakukan dan hasil perbandingan pre test dan post test yang telah dilakukan menunjukkan bahwa masyarakat mengalami peningkatan jawaban benar setelah edukasi dan 
pelatihan dilakukan. Hasil evaluasi pre dan post pelatihan SEFT ditampilkan pada tabel 4.1.

Tekanan darah dapat diartikan adanya kekuatan mendorong darah ke dinding pembuluh darah. Sementara high blood pressure yaitu kondisi dimana tekanan di pembuluh darah arteri lebih tinggi dari yang seharusnya (Olin \& Pharm, 2018). Tekanan darah adalah elemen dasar yang paling sering diukur oleh parameter klinis sebagai bentuk manajemen pasien. Menurut Magder, (2018) tekanan darah dalam arteri ditentukan oleh tiga faktor penting yaitu volume darah dari jantung, elastansi dinding arteri dan kecepatan aliran darah (Magder, 2018). Faktor-faktor tersebut yang akan menilai tekanan darah untuk penentuan keputusan terapeutik. Menurut American Heart Association, (2017) tekanan darah merupakan adanya tekanan yang merangsang aliran darah ke dinding pembuluh darah dan diukur dalam millimeter merkuri (mmHg). Tekanan darah yang tidak normal dapat terjadi karena beberapa faktor yang mempengaruhinya seperti elastisitas dinding arteri, volume darah, kekuatan gerak jantung, viskositas darah, curah jantung dan kapasitas pembuluh darah (Fadlilah et al., 2020).

Faktor-faktor yang mempengaruhi kejadian Hipertensi, kemampuan untuk menerima informasi yang disampaikan dalam sesi pelatihan dan lama menderita hipertensi serta penyakit penyerta yang diderita oleh peserata pelatihan tersaji pada table 3.1. Menurut Berman et al., (2016) faktor yang dapat mempengaruhi tekanan darah antara lain adalah usia, genetik, suhu, obesitas, stres, gaya hidup, olahraga, obatobatan dan kondisi medis (17 Berman 2016 Fundamentals of Nursing, n.d.). Kebiasaan tidur seseorang dan akibatnya bergantung pada karakteristik tidur dengan berbagai faktor, baik fisiologis maupun mental. Menurut Crivello et al., (2019) definisi untuk kualitas tidur sendiri sangat kompleks, kebiasaan tidur seseorang dan akibatnya bergantung pada karakteristik tidur dengan berbagai faktor, baik fisiologis maupun mental. Menurut Crivello et al., (2019) definisi untuk kualitas tidur sendiri sangat kompleks, secara sederhana pengertian kualitas tidur dapat disimpulkan dari hasil teknik pengukuran (Crivello et al., 2019). Teknik objektif dapat menggunakan polisomnografi dan aktigrafi. Sedangkan teknik subjektif menggunakan pengukuran Pittsburgh Sleep Quality Index (PSQI), Consesus Sleep Diary (CSD), Richards Campbell Sleep Questionnaire (RCSQ) dan Karolinska Sleep Diary (KSD).

SEFT merupakan salah satu bentuk mindbody therapy dari terapi komplementer keperawatan sebagai alternatif pengobatan hipertensi (Hidayatulloh \& Lismayanti, 2018). Penelitian yang dilakukan oleh Murni (2018) mengungkapkan bahwa terapi SEFT menggabungkan terapi spiritual dan sistem tubuh (energy medicine) dengan metode tapping (Murni, 2018). Metode ini bekerja merangsang beberapa titik kunci pada sepanjang 12 jalur energi tubuh (energy meridian). Hasil penelitian yang dilakukan oleh Kasron \& Susilawati, (2017) tentang pengaruh Spiritual Emotional Freedom Technique (SEFT) terhadap kualitas tidur penderita hipertensi di Cilacap Selatan menunjukkan sebagian besar responden mengalami peningkatan kualitas tidur yang lebih baik (Susilawati \& Kasron, 2018). Terapi SEFT digunakan untuk menenangkan hati yang diharapkan meningkatkan unsur spiritual dan melepaskan pikiran yang sesak dari unsur emosional (Cholifah et al., 2020). Terapi ini memberikan rasa tenang karena terjadi proses keseimbangan antara energi tubuh sehingga menimbulkan efek relaksasi dan tekanan darah menjadi stabil. Kondisi ini didukung oleh hasil penelitian Huda \& Alvita, (2018) tentang pengaruh terapi SEFT (Spiritual Emotional Freedom Technique) terhadap penurunan tekanan darah pada penderita hipertensi menunjukkan pengaruh terapi SEFT yang signifikan terhadap 
penurunan tekanan darah pada penderita hipertensi (Huda \& Alvita, 2018). Perilaku perawatan hipertensi secara adekuat dapat mencegah dan mengurangi kekambuhan hipertensi sehingga kualitas tidur meningkat (Setyaningrum, 2019).

Penelitian Bach et al., (2019) tentang clinical EFT (Emotional Freedom Technique) improves multiple physiological markers of health menunjukkan efek kesehatan positif serta peningkatan kesejahteraan mental (Bach et al., 2019). Rahmat et al., (2018) menguatkan bahwa terapi SEFT memberikan perbedaan yang lebih bermakna yaitu 75,0\% dengan kualitas tidur lebih baik daripada terapi PMR (Pranowo et al., 2018). Hasil penelitian lain oleh Susilawati \& Kasron, (2018) menyebutkan adanya perbedaan signifikan untuk meningkatkan kualitas tidur pasien hipertensi (Kasron \& Susilawati, 2017). Penelitian Faridah, (2016) menyatakan bahwa terapi SEFT sebagai stimulus awal yang mampu membentuk domain spiritual yang baik sehingga dapat menurunkan tekanan darah pasien hipertensi (Faridah, 2016). Lismayanti \& Sari, (2018) juga mendukung dengan menyatakan adanya perbedaan sebelum dan sesudah dilakukan SEFT pada pasien hipertensi usia di atas 65 tahun (Lismayanti \& Hidayatulloh, 2019). Terapi SEFT dapat digunakan sebagai pengobatan alternatif yang tepat dan praktis pada pasien hipertensi (Rofacky \& Aini, 2015).

\section{SIMPULAN}

Pengaruh terapi SEFT terhadap kualitas tidur pasien hipertensi terbukti signifikan dengan adanya penurunan skor yang berarti kualitas tidur menjadi lebih baik. Pengaruh terapi SEFT terhadap status tekanan darah pasien hipertensi terbukti bermakna dengan adanya perubahan angka sistolik dan diastolik yang cenderung turun sehingga dapat dikatakan status tekanan darah menjadi lebih baik. Hubungan SEFT dengan kualitas tidur dan status tekanan darah pasien hipertensi yaitu SEFT bermanfaat untuk menjaga kestabilan kualitas tidur dan tekanan darah sehari-hari. Sehingga hipotesis penelitian menunjukkan $\mathrm{Ha}$ diterima yaitu ada pengaruh terapi spiritual emotional freedom technique (SEFT) pada kualitas tidur dan status tekanan darah pasien hipertensi.

\section{DAFTAR PUSTAKA}

17 Berman 2016 Fundamentals of Nursing. (n.d.).

93 World Health Organization (WHO) Unknown - Hypertension1. (n.d.).

Ainurrafiq, A., Risnah, R., \& Ulfa Azhar, M. (2019). Terapi Non Farmakologi dalam Pengendalian Tekanan Darah Pada Pasien Hipertensi: Systematic Review. MPPKI (Media Publikasi Promosi Kesehatan Indonesia): The Indonesian Journal of Health Promotion, 2(3), 192-199. https://doi.org/10.31934/mppki.v2i3.8 06

Alfi, W. N., \& Yuliwar, R. (2018). The Relationship between Sleep Quality and Blood Pressure in Patients with Hypertension. Jurnal Berkala Epidemiologi, $6(1), \quad 18$. https://doi.org/10.20473/jbe.v6i12018 .18-26

Alparslan, G. B., Orsal, Ö., \& Unsal, A. (2016). Assessment of sleep quality and effects of relaxation exercise on sleep quality in patients hospitalized in internal medicine services in a university hospital: The effect of relaxation exercises in patients hospitalized. Holistic Nursing Practice, 30(3), 155-165. https://doi.org/10.1097/HNP.0000000 000000147

Bach, D., Groesbeck, G., Stapleton, P., Sims, R., Blickheuser, K., \& Church, D. (2019). Clinical EFT (Emotional Freedom Techniques) Improves Multiple Physiological Markers of Health. Journal of Evidence-Based 
Integrative Medicine, 24, 1-12. https://doi.org/10.1177/2515690X188 23691

Cholifah, N., Sukarmin, \& Kholiq, A. A. (2020). The Effectiveness of the Combination Therapy of Emotional Freedom Technique - Murottal Alqur'an on Blood Pressure of the Elderly with Hypertension. 24(Uphec 2019), $152-157$. https://doi.org/10.2991/ahsr.k.200311 .029

Crivello, A., Barsocchi, P., Girolami, M., \& Palumbo, F. (2019). The Meaning of Sleep Quality: A Survey of Available Technologies. IEEE Access, 7, 167374-167390.

https://doi.org/10.1109/ACCESS.201 9.2953835

Cuspidi, C., Tadic, M., Grassi, G., \& Mancia, G. (2018). Treatment of hypertension: The ESH/ESC guidelines recommendations. Pharmacological Research, 128, 315321.

https://doi.org/10.1016/j.phrs.2017.10 .003

Fadlilah, S., Hamdani Rahil, N., \& Lanni, F. (2020). Analisis Faktor Yang Mempengaruhi Tekanan Darah Dan Saturasi Oksigen Perifer (Spo2). Jurnal Kesehatan Kusuma Husada, Spo 2, 21-30. https://doi.org/10.34035/jk.v11i1.408

Faridah, V. (2016). Perubahan Persepsi Dan Domain Spiritual Terhadap Tekanan Darah Penderita Hipertensi Akibat Pemberian Spiritual Emotional. Surya, 08(01), 60-71.

Hidayatulloh, B., \& Lismayanti, L. (2018). Terapi Spiritual Emotional Freedom Technique ( SEFT ) Menurunkan Tekanan Darah Pasien Hipertensi di UPTD Puskesmas Cilembang Kota Tasikmalaya. 2(1), 4-5.

Huda, S., \& Alvita, G. W. (2018). Pengaruh Terapi Seft (Spiritual Emotional
Freedom Technique) Terhadap Penurunan Tekanan Darah Pada Penderita Hipertensi Di Wilahah Puskesmas Tahunan. Jurnal Keperawatan Dan Kesehatan Masyarakat Cendekia Utama, 7(2), 114. https://doi.org/10.31596/jcu.v7i2.256

Kasron, \& Susilawati. (2017). Pengaruh Spiritual Emotional Freedom Tehnique ( Seft ) Terhadap Kualitas Tidur Penderita Hipertensi Di Cilacap Selatan. Viva Medika, 10, 123-128.

Lismayanti, L., \& Hidayatulloh, B. (2019). Terapi Spiritual Emotional Freedom Technique (SEFT) Menurunkan Tekanan Darah Pasien Hipertensi di UPTD Puskesmas Cilembang Kota Tasikmalaya. Journal of Nursing and Health, 2(1), 15-26. https://doi.org/10.25099/jnh.vol2.iss1. 23

Magder, S. (2018). The meaning of blood pressure 11 Medical and Health Sciences 1102 Cardiorespiratory Medicine and Haematology Luigi Forni. Critical Care, 22(1), 1-10. https://doi.org/10.1186/s13054-0182171-1

Martini, S., Roshifanni, S., \& Marzela, F. (2018). Pola Tidur yang Buruk Meningkatkan Risiko Hipertensi Poor Sleep Pattern Increases Risk of Hypertension. 14(3), 297-303. https://doi.org/http://dx.doi.org/10.30 597/mkmi.v14i3.4181

Murni, -. (2018). Efektivitas Terapi Spritual Emotional Freedom Technique (Seft) Terhadap Penurunan Tekanan Darah Pada Penderita Hipertensi. Photon: Jurnal Sain Dan Kesehatan, 8(2), 151159. https://doi.org/10.37859/jp.v8i2.729

National Heart Lung and Blood Institute / NHLBI. (2020). High Blood Pressure | NHLBI, NIH. Health Topics, High Blood Pressure. 
Olin, B. R., \& Pharm, D. (2018). Hypertension: The Silent Killer: Updated JNC-8 Guideline Recommendations.

Pranowo, S., Rahmat, D., \& Sutarno, . (2018). Perbandingan Antara Progressive Muscle Relaxation dan Spiritual Emotional Freedom Technique Terhadap Kualitas Tidur Pasien Hipertensi. Profesi (Profesional Islam): Media Publikasi Penelitian, 16(1), 17. https://doi.org/10.26576/profesi.279

Riset Kesehatan Dasar Provinsi Jawa Tengah. (2018).

Riskesdas, K. (2018). Hasil Utama Riset Kesehata Dasar (RISKESDAS). In Journal of Physics A: Mathematical and Theoretical (Vol. 44, Issue 8). https://doi.org/10.1088/17518113/44/8/085201
Setyaningrum, R. (2019). Hubungan kualitas tidur dengan tingkat hipertensi pada lansia di dusun sapen umbulmartani ngemplak sleman yogyakarta. Unisa Yogyakarta.

Susilawati, \& Kasron. (2018). Perbandingan Efektifitas Spiritual Emotional Freedom Technique dan Progressive Muscle Relaxation Untuk Meningkatkan Kualitas Tidur Penderita Hipertensi di Cilacap Selatan. 6(1), 1-8.

World Health Organization (WHO). (n.d.). Hypertension. Fact Sheets WHO.

Yani, R. D., Wahyudi, J. T., \& Suratun, S. (2019). Pengaruh Senam Hipertensi Terhadap Kualitas Tidur Pasien Dengan Hipertensi Di Rumah Sakit Muhammadiyah Palembang. Indonesian Journal for Health Sciences, $\quad 3(2), \quad 88$. https://doi.org/10.24269/ijhs.v3i2.184 4 